\title{
A urine-based Exosomal gene expression test stratifies risk of high-grade prostate Cancer in men with prior negative prostate biopsy undergoing repeat biopsy
}

James McKiernan ${ }^{1}$, Mikkel Noerholm², Vasisht Tadigotla², Sonia Kumar², Phillipp Torkler², Grannum Sant ${ }^{2}$, Jason Alter ${ }^{2}$, Michael J. Donovan ${ }^{2,3^{*}}$ (D) and Johan Skog ${ }^{2}$

\begin{abstract}
Background: Initial prostate biopsy often fails to identify prostate cancer resulting in patient anxiety, especially when clinical features such as prostate specific antigen (PSA) remain elevated, leading to the need for repeat biopsies. Prostate biomarker tests, such as the ExoDx ${ }^{T M}$ Prostate (IntelliScore), or EPI test, have been shown to provide individualized risk assessment of clinically significant prostate cancer at initial biopsy; however, the performance in the repeat biopsy setting is not well established.

Methods: As part of a previous prospective clinical validation study evaluating the performance of the EPI test, we collected first-catch, non-DRE urine samples across 22 sites from men with at least one prior negative biopsy scheduled to undergo a repeat prostate biopsy to rule out prostate cancer. All men were 50 years or older with a PSA 2-10 ng/mL. Exosomal mRNA was extracted and expression of three genomic markers, PCA3, ERG and SPDEF was measured. The resulting EPI score was correlated with biopsy results.

Results: 229 men with a prior negative biopsy underwent repeat biopsies. ExoDx Prostate demonstrated good performance ruling out high-grade (Grade group 2, GG2, or higher) prostate cancer (HGPCa) using the previously validated 15.6 cut point in the initial biopsy setting. The EPI test yielded an NPV of 92\% independent of other clinical features and would have avoided $26 \%$ of unnecessary biopsies while missing only five patients with HGPCa (2.1\%). Furthermore, the EPI test provided additional information at a cut-point of 20 and 29.6 with an NPV of 94\%, potentially delaying 35 and $61 \%$ of unnecessary biopsies, respectively. AUC curves and Net Health Benefit Analyses demonstrated superior performance of ExoDx Prostate over PSA and clinical only risk calculators, i.e. ERSPC.

Conclusions: The EPI test provided good performance using the 15.6 cut-point for ruling out HGPCa / GG2 or higher in men undergoing a repeat prostate biopsy with a PSA of 2-10 $\mathrm{ng} / \mathrm{ml}$. Furthermore, the test utilizes gene expression data independent of clinical features to predict the likelihood of HGPCa / GG2 on a subsequent needle biopsy.
\end{abstract}

Keywords: Prostate Cancer, Exosomes, Urine, Early detection, Prostate biopsy

\footnotetext{
* Correspondence: Mjdonovan54@gmail.com

2Exosome Diagnostics, a Bio-Techne Brand, Waltham, MA, USA

${ }^{3}$ Icahn School of Medicine at Mt. Sinai, New York City, NY, USA

Full list of author information is available at the end of the article
}

(c) The Author(s). 2020 Open Access This article is licensed under a Creative Commons Attribution 4.0 International License, which permits use, sharing, adaptation, distribution and reproduction in any medium or format, as long as you give appropriate credit to the original author(s) and the source, provide a link to the Creative Commons licence, and indicate if changes were made. The images or other third party material in this article are included in the article's Creative Commons licence, unless indicated otherwise in a credit line to the material. If material is not included in the article's Creative Commons licence and your intended use is not permitted by statutory regulation or exceeds the permitted use, you will need to obtain permission directly from the copyright holder. To view a copy of this licence, visit http://creativecommons.org/licenses/by/4.0/. The Creative Commons Public Domain Dedication waiver (http://creativecommons.org/publicdomain/zero/1.0/) applies to the data made available in this article, unless otherwise stated in a credit line to the data. 


\section{Background}

Prostate cancer (PCa) is a leading cause of cancer death among men in the United States, with more than 3.6 million men living with prostate cancer. It is estimated that 174,650 newly diagnosed cases occurred in 2019 [1]. Prostate needle biopsies are typically recommended for men with elevated serum PSA levels and/or a suspicious digital rectal exam (DRE) with added considerations based on family history, age, and race. The anxiety, pain, and potential complications associated with prostate biopsy are well documented [2-6]. Furthermore, a large percentage of newly diagnosed prostate cancers are indolent, clinically insignificant, and with low metastatic potential. These cancers typically do not require definitive treatment and may be managed most effectively with Active Surveillance (AS). The low specificity of PSA which contributes to the high frequency of newly-diagnosed low-risk PCa suggests that $60-70 \%$ of men may be able to avoid biopsy [7-10]. Compounding the challenge, the majority of initial biopsy tests do not find cancer [11]. For each negative initial biopsy, it is unknown whether elevated PSA levels and/or a suspicious DRE facilitated the biopsy decision or if the biopsy simply missed a cancerous lesion due to sampling error, tumor heterogeneity and multifocality [12].

The European Randomized Study of Screening for Prostate Cancer (ERSPC) demonstrated that the overdiagnosis and overtreatment of PCa resulting from current practice requires more contemporary and improved methods to identify high-grade disease [13, 14]. Novel diagnostics such as the current test that provide additional clinical value to risk stratify high-grade $\mathrm{PCa}$ (Gleason Grade, or GG $\geq 2$ ) have been developed with a primary objective to avoid biopsies for patients with an increased likelihood of having benign or non-aggressive (GG $\leq 1)$ disease [15-17].

The ExoDx Prostate assay relies on the isolation and analysis of urinary exosomes, which are small lipid bilayer membrane extra-cellular microvesicles (typically $30-200 \mathrm{~nm}$ in diameter) that are secreted from all living cells. Exosomes contain RNA, DNA, and protein, and have been identified in a variety of biofluids such as blood, cerebrospinal fluid, and urine. They are particularly promising for RNA expression profiling given their protected microanatomic environment [18-21]. The ExoDx Prostate (EPI) test has been extensively validated in two prospective multi-center US studies for biopsy naive patients and the signature is generated from quantitative analysis of PCA3 (prostate cancer antigen 3), ERG (V-ets erythroblastosis virus E26 oncogene homologs) and SPDEF RNA $[16,17]$.

The present analysis was designed to evaluate the performance of the ExoDx Prostate gene signature in a cohort of men with a history of prior negative biopsy and now presenting for a repeat biopsy.

\section{Methods}

\section{Study population}

First-catch, non-DRE urine samples were collected at 22 clinical sites (academic and community) in the USA from men with a prior negative prostate biopsy scheduled for a repeat biopsy between June 2014 and April 2015. The men were prostate cancer free, 50 years or older, and undergoing repeat biopsy for either a suspicious DRE and/or PSA level between 2 and $10 \mathrm{ng} / \mathrm{mL}$. Men with a history of invasive treatment for benign prostatic hyperplasia within 6 months or taking medications that affect serum PSA levels within 3-6 months were excluded. The prostate biopsies were reported by the local hospital/practice pathologist who was blinded to ExoDx Prostate results. The study protocol was approved by the Western Institutional Review Board, Olympia, WA and individual academic institutional review boards (Johns Hopkins Hospital, University of Michigan); all study participants provided written informed consent and were not compensated for participating in the study.

\section{Sample collection and processing}

First catch urine samples $(25-50 \mathrm{~mL})$ were stored at $4{ }^{\circ} \mathrm{C}$ for up to 14 days before shipment on ice to the central laboratory (Exosome Diagnostic Laboratory, Waltham, MA). At the Exosome Diagnostics CLIA Laboratory, samples were filtered $(0.8 \mathrm{um})$ and stored at $-80^{\circ} \mathrm{C}$ until further processing which included exosome isolation and concentration by ultrafiltration centrifugation.

For each sample, exosomal RNA was extracted, and the RNA copy numbers of ERG, PCA3, and SPDEF determined. The methodology for urinary exosome isolation, primer generation, RNA extraction and normalization as well as reverse transcriptase polymerase chain reaction have been previously reported in an original analytic and technical feasibility study by Donovan et al., 2015 [14] and in two subsequent independent validation studies $[15,16]$ of which the McKiernan et al., 2016 [15] provided the prior negative patients included in the current analysis. The test result is calculated based on the relative gene expression of these three genes, without inclusion of other clinical parameters, and provides a risk score (scale 0$100)$ that predicts the presence of HGPCa ( $\geq G G 2)$. Men with a score $\geq 15.6$ (or 20) are at increased risk for having HGPCa on a subsequent biopsy.

\section{Statistical analysis}

Evaluate ability of the EPI assay to predict GG 2 or higher prostate cancer $(\mathrm{PCa})$ on repeat biopsy in men with a history of a prior negative biopsy and a PSA level 2-10 ng/mL. Area under the Receiver operating characteristics (AUC-ROC) curves for PSA vs. the EPI test are utilized as a measure of clinical performance. A well- 
established risk calculator (RC), The European Randomized Study of Screening for Prostate Cancer (ERSPC) RCs was utilized to further determine risk of GG2 or higher PCa using available clinical parameters [14, 22]. As prostate volume is not generally obtained, the ERSPC RC DRE is used as a surrogate for prostate volume [23]. Missing DRE results were imputed as nonsuspicious. The initial biopsy 15.6 cut point from two prior prospective studies $[16,17]$ was utilized in the repeat biopsy setting and compared to the EPI cut points of 20 (adjusted cutpoint from the first validation study [16] and 29.6 (adjusted cutpoint), using sensitivity, specificity, negative predictive value (NPV), and positive predictive value (PPV). EPI test was also assessed with a decision curve analysis to investigate the net health benefit for predicting GG2 or higher PCa [24]. The datasets analyzed during the current study may be available from the corresponding author on reasonable request.

\section{Results}

\section{Study population and biopsy outcome}

Between June 2014 and April 2015, non-DRE, first catch urine samples were collected from 1563 participants enrolled in a prospective validation study of the ExoDx Prostate test for men undergoing initial diagnostic prostate biopsy with a PSA between 2 and $10 \mathrm{ng} / \mathrm{mL}$. The enrollment included patients with a prior negative biopsy however they were excluded in the validation analysis by design. Here we show the outcome in the population that had at least one prior negative biopsy. Urine samples from subjects who had incomplete data and/or $>49 \mathrm{ml}$ were excluded of which all were initial biopsy patients. There were no patients excluded from the prior negative biopsy cohort. 229 patients met the criteria for the 'Intended Use Population': a prior negative biopsy and "gray zone" serum PSA levels $(2-10 \mathrm{ng} / \mathrm{mL})$. The median age was 65 years, and median pre-biopsy serum PSA was $6.1 \mathrm{ng} / \mathrm{mL}$ (Table 1). Most subjects had no family history of $\mathrm{PCa}(75.1 \%)$ and $66.4 \%$ had a nonsuspicious DRE with 71.6\% of subjects of Caucasian descent and 14.4\% African American. Of the 229 patients, $90 \%$ underwent a 12-core, transrectal ultrasound-guided prostate needle biopsy using a standard template with diagnosis performed at site affiliated pathology practices without a central pathology review. The total positive biopsy rate was $31 \%(n=72): 19 \%(n=44)$ GG1 and $12 \%$ $(n=28) \geq \mathrm{GG} 2$ with $69 \%$ benign biopsies.

\section{EPI PERFORMANCE IN PREDICTING $\geq$ GG2 PCa}

In 229 men undergoing repeat biopsy for a prior negative biopsy, the ExoDx Prostate test with the prior validated cut point of 15.6 (for the initial biopsy) demonstrated good performance in discriminating HGPCa, GG2 or higher from low-grade prostate cancer (Gleason 6, GG1)
Table 1 Demographic and clinical characteristics of prior negative biopsy cohort

\begin{tabular}{ll}
\hline Total Cohort, N & 229 \\
Median Age (IQR) & $65(60-70)$ \\
Median PSA ng/mL (IQR) & $6.1(4.71-7.5)$ \\
Family History, N (\%) & $172(75.1 \%)$ \\
Ethnicity, N (\%) & \\
African Americans & $33(14.4 \%)$ \\
Asian/Pacific Islander & $4(1.7 \%)$ \\
Caucasian & $164(71.6 \%)$ \\
Hispanic & $17(7.4 \%)$ \\
Other & $11(4.8 \%)$ \\
DRE non-suspicious, N (\%) & $152(66.4 \%)$ \\
Grade Groups, N (\%) & \\
Benign & $157(68.6 \%)$ \\
GG1 & $44(19.2 \%)$ \\
GG2 & $17(7.4 \%)$ \\
GG3 & $6(2.6 \%)$ \\
GG4 & $4(1.4 \%)$ \\
GG5 & $1(0.4 \%)$ \\
\hline
\end{tabular}

and benign disease on biopsy. The assay performance in the prior negative patients showed an NPV and sensitivity of $92 \%$ (95\%CI, 0.81-0.97) 82\%, respectively. An EPI score less than or equal to 15.6 would have avoided $26 \%$ of all biopsies (i.e. 59 of 229) or $27 \%$ of unnecessary biopsies (i.e. true negative or specificity) and delayed detection of $\geq$ GG2 disease in 5 men (2.1\%) (Table 2). Importantly, only 3 men with GG3 or higher (1\%) would have delayed detection in the repeat biopsy setting. Using an EPI score of $\leq 20$ or $\leq 29.6$ would have avoided biopsies in $35 \%$ (i.e. 80 of 229 ) and $61 \%$ (i.e. 140 of 229 ) or 37 and $65 \%$, respectively of unnecessary biopsies, thereby reducing anxiety and potential complications associated with an unnecessary biopsy. It is important to keep in mind that with the cut-point adjustments other measures of accuracy and performance will change, notably applying a cut-point of 29.6 will decrease the sensitivity to $68 \%$ while using either the 15.6 or 20 will yield comparable NPV and sensitivity while increasing the number of unnecessary biopsies from $26 \% \wedge$ to $37 \%$ with the 20 cut-point.

On comparing the performance of the EPI test (AUC 0.66, 95\%CI: 0.55-0.78) with alternative models, the EPI test was superior to PSA only (AUC 0.54, 95\%CI: 4366), and the ERSPC-RC (AUC 0.47, 95\%CI: 0.36-0.58), for predicting $\geq$ GG2 $\mathrm{PCa}$, (Fig. 1a).

We also investigated the clinical value of the EPI test relative to alternative models using a decision curve analysis (Fig. 1b). EPI's performance was superior (highest net benefit) to all models tested, including PSA and ERSPC-RC. 
Table 2 Projected impact of the validated EPI 15.6 and adjusted cut-points 20 and 29.6 (with presumed 100\% compliance) on expected biopsies performed and avoided

\begin{tabular}{|c|c|c|c|c|c|c|c|}
\hline $\begin{array}{l}\text { EPI cut } \\
\text { point }\end{array}$ & $\begin{array}{l}\text { Expected Biopsies } \\
\text { Performed }\end{array}$ & $\begin{array}{l}\text { Expected Biopsies } \\
\text { Avoided }\end{array}$ & $\begin{array}{l}\text { Delayed } \\
\text { GG2 }\end{array}$ & $\begin{array}{l}\text { Delayed } \\
\geq \text { GG3 }\end{array}$ & NPV & Sensitivity & Specificity \\
\hline 15.6 & 170 (74\%) & 59 (26\%) & 2 & 3 & $\begin{array}{l}91.5(81.3- \\
97.2)\end{array}$ & $\begin{array}{l}82.1(63.1- \\
93.9)\end{array}$ & $\begin{array}{l}26.9(20.9- \\
33.6)\end{array}$ \\
\hline 20 & 149 (65\%) & 80 (35\%) & 2 & 3 & $\begin{array}{l}93.8(86.0- \\
97.9)\end{array}$ & $\begin{array}{l}82.1(63.1- \\
93.9)\end{array}$ & $\begin{array}{l}37.3(30.6- \\
44.4)\end{array}$ \\
\hline 29.6 & 89 (39\%) & 140 (61\%) & 2 & 6 & $\begin{array}{l}93.6(88.1- \\
97.0)\end{array}$ & $\begin{array}{l}67.9(47.6- \\
84.1)\end{array}$ & $\begin{array}{l}65.2(58.2- \\
71.7)\end{array}$ \\
\hline
\end{tabular}

\section{Discussion}

Over 1 million transrectal ultrasonography guided (TRUS) prostate biopsies are performed annually in the US and Europe [6]. Although clinical information such as age, race, family history, or a suspicious DRE are triggers, most TRUS biopsies are driven by PSA screening. Biopsies are often associated with pain, bleeding, sepsis and, of significant concern, an increasing rate of antibiotic resistant infection [6, 25]. A significant number (approximately 70\% of men) are not found to have prostate cancer on initial biopsy, and this leads to patient anxiety because of the false negative rate as a result of prostatectomy under-sampling and tumor heterogeneity/multifocality. These concerns drive many men to undergo repeat biopsy. In fact, the Surveillance, Epidemiology, and End Results (SEER) data indicates that $\sim 12 \%$ of men with a prior negative biopsy have a repeat biopsy within 1 year and $44 \%$ of men younger than 70 years old have a repeat biopsy [26].

The ExoDx (EPI) Prostate test is a urine-based genomic assay which uses the expression levels of three genes (ERG,
PCA3 and SPDEF) involved in PCa initiation and progression, to predict risk of HGPCa, independent of clinical features or standard of care (SOC) [27-33].. The test algorithm was developed and validated on the intended use cohort, i.e. men presenting for their initial biopsy with a PSA $2-10 \mathrm{ng} /$ $\mathrm{mL}$ where it achieved an NPV of $91 \%$, a sensitivity of 91 and $34 \%$ specificity [16]. A recent blinded control arm utility study demonstrated that the EPI test reduced the number of biopsies when the test was negative, and helped to identify $30 \%$ more high-grade prostate cancers compared to the control arm without the EPI test result [34]. It is well established in the literature that prevalence of prostate cancer is significantly lower in a prior negative biopsy population and that this clinical feature will favorably impact test performance when included in risk assessment models (and some commercial assays) [35, 36]. To address this issue, we evaluated the accuracy of EPI in the prior negative biopsy population using the AUC and compared results with PSA alone and a well-established risk calculator, the European Randomized
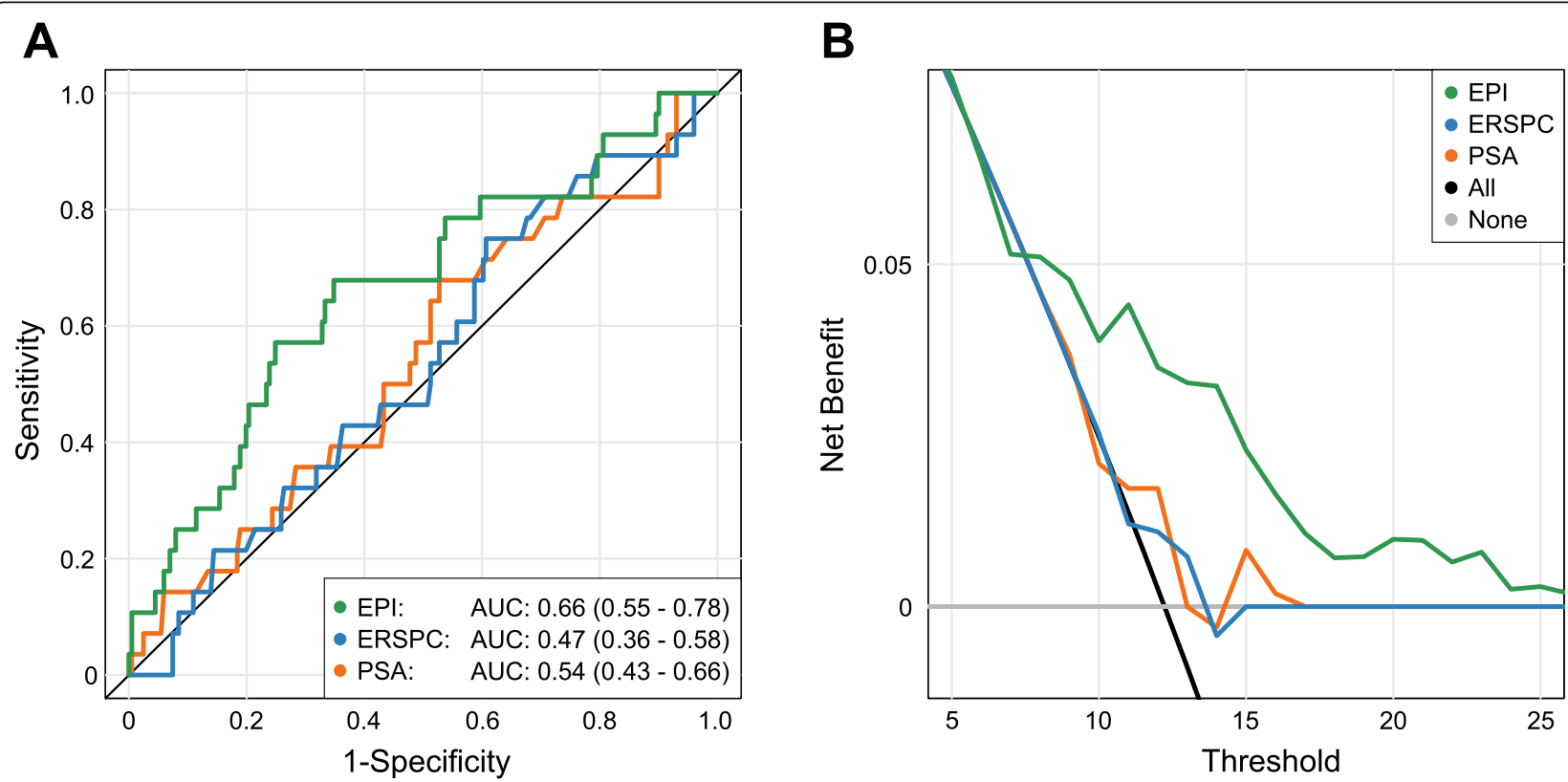

Fig. 1 Area under receiver operating characteristic (AUC) curves are shown to compare performances of EPI in (a) the current cohort ( $n=229$ ) with the ERSPC, and PSA alone. The corresponding net benefit analysis for this cohort is shown in $\mathbf{b}$. EPI = ExoDx Prostate (IntelliScore); ERSPC = European Randomized Study of Screening for prostate cancer (risk calculator); PSA = prostate-specific antigen 
Study of Screening for Prostate Cancer (ERSPC) [13, 14]. EPI had a superior AUC of 0.66 vs PSA AUC 0.54, and ERSPC AUC 0.47. As EPI is independent of all clinical features it represents an independent biological assessment of prostate cancer risk.

In addition to the AUC we also employed a decision curve analysis which considers overall net health benefit of various biomarkers and risk assessment tools. When EPI was compared with PSA and clinical-only models such as the ERSPC, a higher net benefit was observed at a biopsy threshold probability of $10 \%$, and maintained up to a maximum biopsy rate of $30 \%$. In contemporary practice the decision to proceed with a biopsy is a delicate balance between the risk associated with the biopsy procedure vs. the risk of missing a potentially clinically significant cancer. The benefit for a test such as EPI is that the risk score is a biological construct independent of all clinical factors thereby allowing for combination with other variables such as race, family history and an underlying disease.

In the current prior negative biopsy population, an EPI risk score less than 15.6 would have potentially avoided biopsy in $26 \%$ of men based on total number of biopsies in the study (i.e. 229) and a score of less than 20 would have avoided a biopsy in $35 \%$ of men without missing additional GG2 or higher PCa. Furthermore, if we equate benign and Grade Group 6 biopsy outcomes as unnecessary biopsies, the $<15.6$ and $<20$ cut-points would represent 27 and 37\% unnecessary biopsies, respectively. Furthermore, as per the 2020 NCCN Early Detection of Prostate Cancer Guidelines [37], it is clinically important to differentiate GG2 vs GG3 PCa which is relevant for the performance of EPI as only 3 patients with GG3 or higher disease were missed at either the 15.6 or the 20 cut-point vs. 6 individuals (3\%) with the 29.6 cut-point. The EPI assay also generated a comparable NPV of 92 and $94 \%$ in the prior negative biopsy population (cut-points 15.6 and 20 , respectively) vs. 91 and $89 \%$ in the two prior initial biopsy validation studies $[16,17]$.

Study limitations include the sample size and lack of a central pathology review, which may have introduced some variability, specifically when reporting small volume cancers and the fact that there were no men in the study who underwent multi-parametric MRI imaging pre-biopsy. During the study period (2014 and 2015), MRI imaging was not standard of care in the USA. Nevertheless, all the study participating centers represent large urology group practices and academic centers with highly experienced uropathologists. A second prospective study in prior negative biopsy men is underway in the US to address the increasing use of mpMRI imaging and fusion biopsy in this population.

\section{Conclusion}

The ExoDx Prostate (IntelliScore) EPI test is a validated, non-invasive urine exosome gene expression assay that performs equally well for men at initial biopsy or with a history of at least one prior negative biopsy. The gene expression assay is more accurate than existing risk assessment methods, is not dependent on clinical features, and informs decision-making at both initial and or repeat biopsy time-points.

\section{Abbreviations}

PCA3: Prostate cancer antigen 3; ERG: ETS (erythroblast transformationspecific) -related gene; SPDEF: SAM pointed domain-containing ETS transcription factor

\section{Acknowledgements}

We would like to thank the various urology practices, investigators, and laboratory/support personnel for assisting in patient accrual, data collection and EPI report generation.

\section{Authors' contributions}

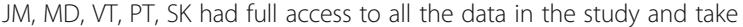
responsibility for the integrity of the data and the accuracy of the data analysis. Drs JM, MD contributed equally to this research and article. Study concept and design: JM, MD, JK, PT, MN. Acquisition, analysis, or interpretation of data: JM, MD, JS, VT, PT, MN. Drafting of the manuscript: JA, VT, SK, MD, SK, PT, MN. Critical revision of the manuscript for important intellectual content: JA, MD, GS, SK, MN, PT, VT, JS. Statistical analysis: VT, PT, JS, MD. Obtained funding: Exosome Diagnostics. Administrative, technical, or material support: JM, SK. Study supervision: JM, MD, JS. All Authors have read and approved the manuscript

\section{Funding}

Exosome Diagnostics, the developer and owner of the ExoDx Prostate IntelliScore (EPI) urine exosome gene expression assay used in this study, provided all financial and material support for the work reported in this article.

\section{Availability of data and materials}

The datasets during and/or analyzed during the current study may be available from the corresponding author on reasonable request.

\section{Ethics approval and consent to participate}

The study protocol was approved by the Western Institutional Review Board, Olympia, WA and individual academic institutional review boards (Johns Hopkins Hospital, University of Michigan); all study participants provided written informed consent and were not compensated for participating in the study.

Consent for publication

Not Applicable.

\section{Competing interests}

M Noerholm, V Tadigotla, S Kumar, P Torkler, J Alter, J Skog are employees of Exosome Diagnostics, a Bio-Techne Brand; M Donovan and G Sant are consultants to Exosome Diagnostics.

\section{Author details}

${ }^{1}$ Columbia University Medical Center, New York City, NY, USA. ${ }^{2}$ Exosome Diagnostics, a Bio-Techne Brand, Waltham, MA, USA. ${ }^{3}$ Icahn School of Medicine at Mt. Sinai, New York City, NY, USA.

Received: 1 May 2020 Accepted: 26 August 2020

Published online: 01 September 2020

References

1. Miller $K D$, Nogueira $L$, Mariotto $A B$, et al. Cancer treatment and survivorship statistics, 2019. CA Cancer J Clin. 2019:69:363-85.

2. Bjurlin MA, Wysock JS, Taneja SS. Optimization of prostate biopsy: review of technique and complications. Urol Clin North Am. 2014:41:299-313.

3. Lundstrom KJ, Drevin L, Carlsson S, Garmo H, Loeb S, Stattin P, et al. Nationwide population-based study of infections after transrectal ultrasound-guided prostate biopsy. J Urol. 2014;192:1116-22. 
4. Nam RK, Saskin R, Lee Y, Liu Y, Law C, Klotz LH, et al. Increasing hospital admission rates for urological complications after transrectal ultrasoundguided prostate biopsy. J Urol. 2010;183:963-8.

5. Bruyere F, Malavaud S, Bertrand P, Decock A, Cariou G, Doublet JD, et al. Prosbiotate: a multicenter, prospective analysis of infectious complications after prostate biopsy. J Urol. 2014;193:145-50.

6. Loeb S, Vellekoop A, Ahmed HU, Catto J, Emberton M, Nam R, et al. Systematic review of complications of prostate biopsy. Eur Urol. 2013;64:876-92

7. Abouassaly R, Thompson IM Jr, Platz EA, Klein EA. Epidemiology, etiology, and prevention of prostate cancer. In: WS MD, Wein A, Kavoussi L, Novick AC, Partin AW, Peters CA, et al., editors. Campbell-Walsh Urology. 10th ed. Philadelphia: Elsevier Saunders; 2012.

8. Berman DM, Epstein Jl. When is prostate cancer really cancer? Urol Clin North Am. 2014;41:339-46.

9. Klotz L. Active surveillance versus radical treatment for favorable-risk localized prostate cancer. Curr Treat Options in Oncol. 2006;7:355-62.

10. Getzenberg RH, Partin AW. Prostate cancer tumor markers. In: Wein AJ, Kavoussi LR, Novick AC, Partin AW, Peters CA, editors. Campbell-Walsh urology. 10th ed. Philadelphia: Elsevier Saunders; 2012.

11. Ahmed HU, El-Shater BA, Brown LC, Gabe R, Kaplan R, Parmar MK, et al. Diagnostic accuracy of multi-parametric MRI and TRUS biopsy in prostate cancer (PROMIS): a paired validating confirmatory study. Lancet. 2017; 389(10071):815-22.

12. Welch $H G$, Fisher ES, Gottlieb DJ, Barry MJ. Detection of prostate cancer via biopsy in the Medicare-SEER population during the PSA era. J Natl Cancer Inst. 2007;99:1395-400.

13. Schroder FH, Hugosson J, Roobol MJ, Tammela TL, Zappa M, Nelen V, et al. Screening and prostate cancer mortality: results of the European randomized study of screening for prostate cancer (ERSPC) at 13 years of follow-up. Lancet. 2014;384:2027-35.

14. Foley RW, Maweni RM, Gorman L, et al. European randomized study of screening for prostate cancer (ERSPC) risk calculators significantly outperform the Prostate Cancer Prevention Trial (PCPT) 2.0 in the prediction of prostate cancer: a multi-institutional study. BJU. 2016;118:706-13.

15. Donovan MJ, Noerholm M, Bentink $S$, et al. A molecular signature of PCA3 and ERG exosomal RNA from non-DRE urine is predictive of initial prostate biopsy result. PCPD. 2015;18:370-5.

16. McKiernan J, Donovan MJ, O'Neill V, et al. A novel urine exosome gene expression assay to predict high-grade prostate cancer at initial biopsy. JAMA Oncol. 2016;2(7):1-8.

17. McKiernan J, Donovan MJ, Margolis E, et al. A prospective adaptive utility trial to validate performance of a novel urine exosome gene expression assay to predict high-grade prostate cancer in patients with prostatespecific antigen 2-10 ng/mL at initial biopsy. Eur Urol. 2018;74:731-8.

18. van der Vos KE, Balaj L, Skog J, Breakefield XO. Brain tumor microvesicles: insights into intercellular communication in the nervous system. Cell Mol Neurobiol. 2011;31:949-59.

19. Nilsson J, Skog J, Nordstrand A, Baranov V, Mincheva-Nilsson L, Breakefield $\mathrm{XO}$, et al. Prostate cancer-derived urine exosomes: a novel approach to biomarkers for prostate cancer. Br J Cancer. 2009;100:1603-7.

20. Skog J, Wurdinger T, van Rijn S, Meijer DH, Gainche L, Sena-Esteves M, et al. Glioblastoma microvesicles transport RNA and proteins that promote tumour growth and provide diagnostic biomarkers. Nat Cell Biol. 2008;10: 1470-6.

21. Valadi H, Ekstrom K, Bossios A, Sjostrand M, Lee JJ, Lotvall JO. Exosomemediated transfer of mRNAs and microRNAs is a novel mechanism of genetic exchange between cells. Nat Cell Biol. 2007;9:654-9.

22. Ankerst DP, Hoefler J, Bock S, et al. Prostate cancer prevention trial risk calculator 2.0 for the prediction of low vs. high-grade prostate cancer. Urology. 2014;83:1362-7.

23. Roobol MJ, Schröder FH, Hugosson J, et al. Importance of prostate volume in the European randomised study of screening for prostate Cancer (ERSPC) risk calculators: results from the prostate biopsy collaborative group. World $J$ Urol. 2012:30:149-55.

24. Vickers AJ, Elkin EB. Decision curve analysis: a novel method for evaluating prediction models. Med Decis Mak. 2006;26(6):565-74.

25. Feliciano J, Teper $E$, Ferrandino $M$, et al. The incidence of fluoroquinolone resistant infections after prostate biopsy--are fluoroquinolones still effective prophylaxis? J Urol. 2008;179(3):952-5.

26. Loeb $\mathrm{S}$. When is a negative prostate biopsy really negative? Repeat biopsies in detection and active surveillance. J Urol. 2017;197:973-4.
27. Wei JT, Feng Z, Partin AW, et al. Can urinary PCA3 supplement PSA in the early detection of prostate cancer? J Clin Oncol. 2014;32(36):4066-72.

28. Gittelman MC, Hertzman B, Bailen J, et al. PCA3 molecular urine test as a predictor of repeat prostate biopsy outcome in men with previous negative biopsies: a prospective multicenter clinical study. J Urol. 2013;190(1):64-9.

29. Leyten $\mathrm{GH}$, Hessels $\mathrm{D}$, Jannink $\mathrm{SA}$, et al. Prospective multicentre evaluation of PCA3 and TMPRSS2-ERG gene fusions as diagnostic and prognostic urinary biomarkers for prostate cancer. Eur Urol. 2014;65(3):534-42.

30. Cheng XH, Black M, Ustiyan V, et al. SPDEF Inhibits Prostate Carcinogenesis by Disrupting a Positive Feedback Loop in Regulation of the Foxm1 Oncogene. PLoS Genet 2014; 10(9): https://doi.org/10.1371/journal.pgen.1004656.

31. Haller AC, Tan W, Payne-Ondracek R, et al. High SPDEF may identify patients who will have a prolonged response to androgen deprivation therapy. Prostate. 2014;74(5):509-19.

32. St John J, Powell K, Conley-Lacomb MK, et al. TMPRSS2-ERG fusion gene expression in prostate tumor cells and its clinical and biological significance in prostate Cancer progression. J Cancer Sci Ther. 2012;4(4):94-101.

33. Hagen RM, Adamo P, Karamat S, et al. Quantitative analysis of ERG expression anz.D its splice isoforms in formalin-fixed, paraffin-embedded prostate cancer samples: association with seminal vesicle invasion and biochemical recurrence. Am J Clin Pathol. 2014;142(4):533-40.

34. Tutrone R, Donovan MJ, Torkler $\mathrm{P}$, et al. Clinical utility of the exosome based ExoDx prostate (Intelliscore) EPI test in men presenting for initial biopsy with a PSA 2-10 ng/mL. Prostate cancer and Prostatic Diseases; 2020. https://doi.org/10.1038/s41391-020-0237.

35. Parekh DJ, Punnen S, Sjoberg SD, et al. A multi-institutional prospective trial in the USA confirms that the $4 \mathrm{kscore}$ accurately identifies men with highgrade prostate cancer. Eur Urol. 2015;68:464-70

36. Neste LV, Hendriks RJ, Dijkstra S, et al. Detection of high-grade prostate cancer using a urinary molecular biomarker-based risk score. Eur Urol. 2016; 70(5):740-8.

37. Prostate Cancer Early Detection. National Comprehensive Cancer Network version 2.2020 - July 24, 2020.

\section{Publisher's Note}

Springer Nature remains neutral with regard to jurisdictional claims in published maps and institutional affiliations.

\section{Ready to submit your research? Choose BMC and benefit from:}

- fast, convenient online submission

- thorough peer review by experienced researchers in your field

- rapid publication on acceptance

- support for research data, including large and complex data types

- gold Open Access which fosters wider collaboration and increased citations

- maximum visibility for your research: over $100 \mathrm{M}$ website views per year

At $\mathrm{BMC}$, research is always in progress.

Learn more biomedcentral.com/submissions 